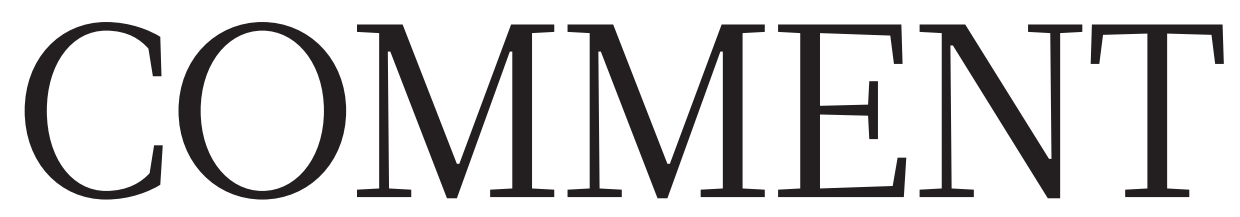

CLIMATE Nations vulnerable to global warming should steer geoengineering research $\mathbf{p . 2 2}$
HEALTH Jim O’Neill hails Hans Rosling's swansong on the predictive power of data $\mathbf{p . 2 5}$
SATIRE Happy 90th, Tom Lehrer, songwriter and mathematician $\mathbf{p . 2 7}$
OBITUARY Günter Blobel, protein-postcode Nobel laureate, remembered p.32

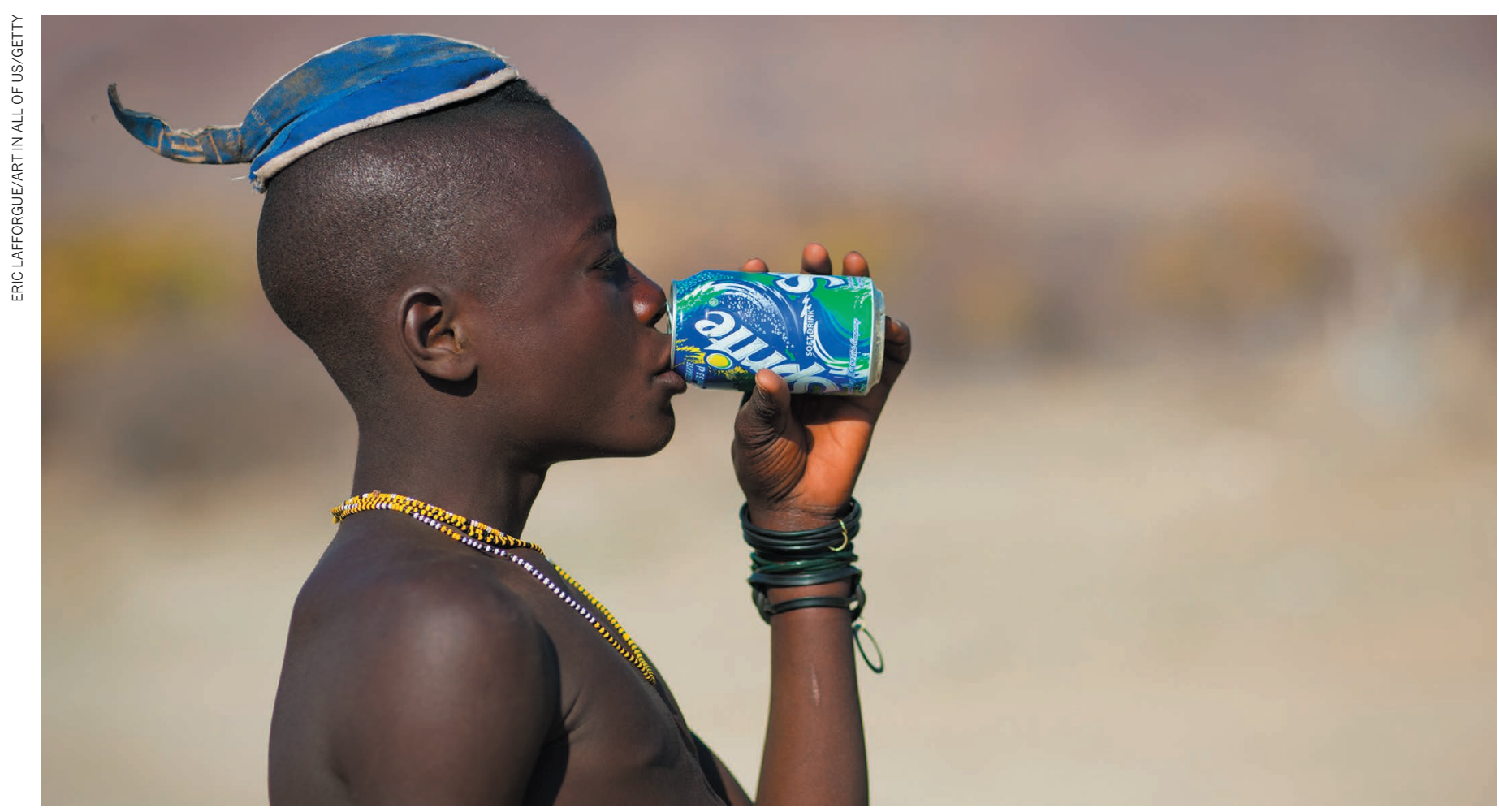

To reduce people's consumption of added sugar, various governments have introduced a tax on sweetened drinks.

\title{
Reward food companies for improving nutrition
}

Governments must provide incentives for businesses to fix the global food system, not just punish them for acting irresponsibly, argues Lawrence Haddad.

\section{$\mathrm{T}$} This month, the UK government introduces the Soft Drinks Industry 1 Levy. Producers, packagers and importers of beverages that contain 5 grams of sugar or more per 100 millilitres will have to pay a tax. Some might increase their prices to cover the cost, which could discourage buyers. The hope is that most firms will make their products less sweet to avoid it.

More than 20 countries now apply some variant of a 'sugar tax'. Various studies show that it can reduce people's consumption of added sugar ${ }^{1,2}$. After Mexico's government introduced a tax on sweetened drinks in 2014, for instance, sales in 2015 fell by nearly $10 \%$ (ref. 3).

Such 'sticks', policies that punish food and drink companies for harming people's nutrition, are popular with governments, United Nations agencies, non-governmental organizations and others. But in my view, a fundamental - and often justified - distrust of industry means that those trying to fix food systems are missing opportunities to encourage private-sector businesses to do more good things for nutrition, not just fewer bad things. We should use 'policy carrots' too.

\section{HISTORY OF DISTRUST}

Over the past few decades, many of those who work to improve people's nutrition have seen businesses as part of the problem, not as an essential part of the solution. Much of the wariness stems from how companies have promoted breast-milk substitutes and sugary drinks.

Since 1981, the International Code of Marketing of Breast-milk Substitutes 
has sought to protect the exclusive breastfeeding of infants younger than six months, and to position it as a complement to other foods for older infants. Adopted by the World Health Assembly, the decisionmaking body of the World Health Organization (WHO), the code aims to shield mothers, health workers and health-care systems from commercial promotion that undermines breastfeeding.

Yet producers in some countries often violate this code, for example by encouraging health facilities to include formula milk in the packs given to new mothers or by offering it free or discounted to pregnant women ${ }^{4}$.

The marketing and lobbying techniques used by some producers of sugary drinks to target children are similarly scandalous. Examples include branding educational materials, embedding advertisements for unhealthy food in computer games, or using toys to market such foods to children in restaurants ${ }^{5}$. Such drinks significantly increase people's risk of developing type 2 diabetes, heart disease and other chronic conditions. Some producers also refuse to take at least some responsibility for the rise in obesity throughout Latin America, Africa and Asia - a trend that correlates with an upswing in the consumption of soft drinks in these regions over the past 15 years.

These flashpoints in nutrition probably explain why policy carrots are rarely deployed, despite numerous studies indicating their potential value ${ }^{6}$. Of the countries that informed the WHO about their fiscal policies to promote healthy diets in 2016-17, more than half had increased taxes on unhealthy foods and beverages. Less than one-quarter had introduced subsidies to lower the cost of healthier alternatives ${ }^{7}$.

But businesses are the main investors in the world's food systems. In 2016, Hershey and General Mills each spent more than US $\$ 500$ million on advertising alone (see go.nature.com/2u3jttr). In 2014, international aid donors spent just $\$ 50$ million in total on combating dietrelated chronic disease ${ }^{8}$ (see 'Top investors').

Punitive policies, government guidelines on eating healthily and legislation for food safety won't be enough to alter food systems such that more people are better nourished. Governments must also give incentives to the main investors in such systems so that they play a much more positive part in improving nutrition.

\section{WORKING TOGETHER}

For 25 years, I worked solely in the public sector. I now direct a non-governmental organization that supports public-private approaches to promote the availability, affordability and desirability of nutritious food - the Global Alliance for Improved Nutrition (GAIN) in Geneva, Switzerland.
Just 18 months in the job has convinced me that many in the private sector are willing to adjust their businesses to make money and improve people's nutrition at the same time.

Some heads of companies have their own reasons, such as diet-related chronic disease in their family. For other companies, dedicating resources to causes such as nutrition can pull in talented and driven employees. Overall, I have been struck by the commitment, knowledge and integrity of many in this newly discovered private-sector 'tribe'.

Public-private collaborations could improve nutrition in many ways. The top 10 multinationals produce more than $50 \%$ of all soft drinks. But the top 10 'packaged food' companies - which supply branded products sold in shops and supermarkets account for only $15 \%$ of these sales in the world ${ }^{9}$. So those in the public sector should work with small, medium and large national companies, not just the vast multinationals. Partnerships could even involve companies that aren't in the food sector.

Mobile-phone companies, for instance, can send people government-approved text messages about how to eat healthily, or spread links to information about healthy diets. By providing this public service, they attract more customers ${ }^{10}$. Such an approach is being tried in Tanzania, Bangladesh and Ghana with the coordination of GSMA, the membership organization for more than 300 mobile-phone providers.

Likewise, marketing and advertising companies can help those in the public sector to improve the 'stickiness' of media messaging around nutrition. As an example, in 2014,

\section{TOP INVESTORS}

Globally, companies have much deeper pockets for food promotion than have governments and non-governmental organizations.

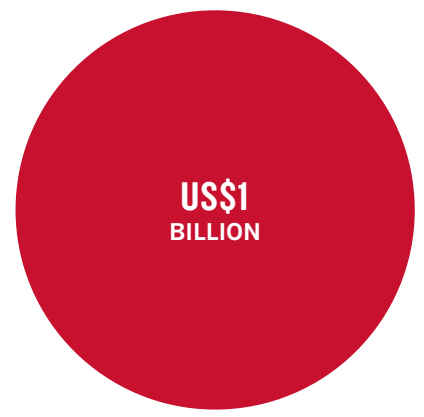

Advertising spend of just 2 of the top 25 US food and beverage companies (Hershey and General Mills) in 2016.

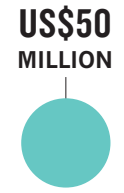

International aid invested in nutrition-related diseases in 2014. the Indonesian government collaborated with a creative agency in Indonesia, GAIN and the London School of Hygiene and Tropical Medicine. The result was a oneminute video during which a mother gossips about how everyone else is failing to feed their children properly. The use of humour and emotion seemed to work, in contrast to standard government-produced instructions about what people should be eating. An independent evaluation of the campaign indicated that it helped $50 \%$ of the 6- to 23-month-old infants in the assessed villages to meet a nutrient adequacy threshold, compared with $36 \%$ of infants in the control villages ${ }^{11}$.

Companies that specialize in food transport or packaging can help to reduce food loss during storage and distribution using relatively low-cost technologies, such as repurposed storage containers or cheap insulating materials. (Perishable foods such as fruit tend to be higher in micronutrients than longer lasting ones such as cereals.) Last year, led by the Lagos state government, we at GAIN connected tomato farmers in Nigeria with commercial suppliers of reusable plastic crates. Studies in Asia have shown that such crates, used in place of wicker baskets, can reduce the loss of fruits and vegetables along the supply chain from $30-50 \%$ to $5 \%$ (ref. 12).

With a mix of public- and private-sector technical and financial assistance, small- and medium-sized businesses in, say, horticulture and aquaculture could make their products more available, affordable, desirable and profitable. Since 2013, GAIN has been working with around 500 such firms to get more servings of nutritious foods (such as beans, fish, peanuts and chicken) into markets in five countries in Africa and Asia, and to make those servings cheaper. Independent evaluations show some achievements. For example, one firm in Kenya has helped to make tilapia fish affordable for $68 \%$ of the population (up from 49\%) in the region where it is operating ${ }^{13}$.

\section{FIVE STEPS TO BETTER FOOD}

So how do governments and others that are striving to improve nutrition identify and seize opportunities to change behaviours? Five things need to be done.

Support businesses that work with nutritious foods. Governments frequently create export-processing zones or business parks with reduced rents or tariffs for exported goods, say, to promote business types that boost economic growth. So why not create business parks for producers of nutritious foods, with lower rents and taxes and cheaper electricity and water supplies?

Most of the small- and medium-sized businesses aiming to become the next 


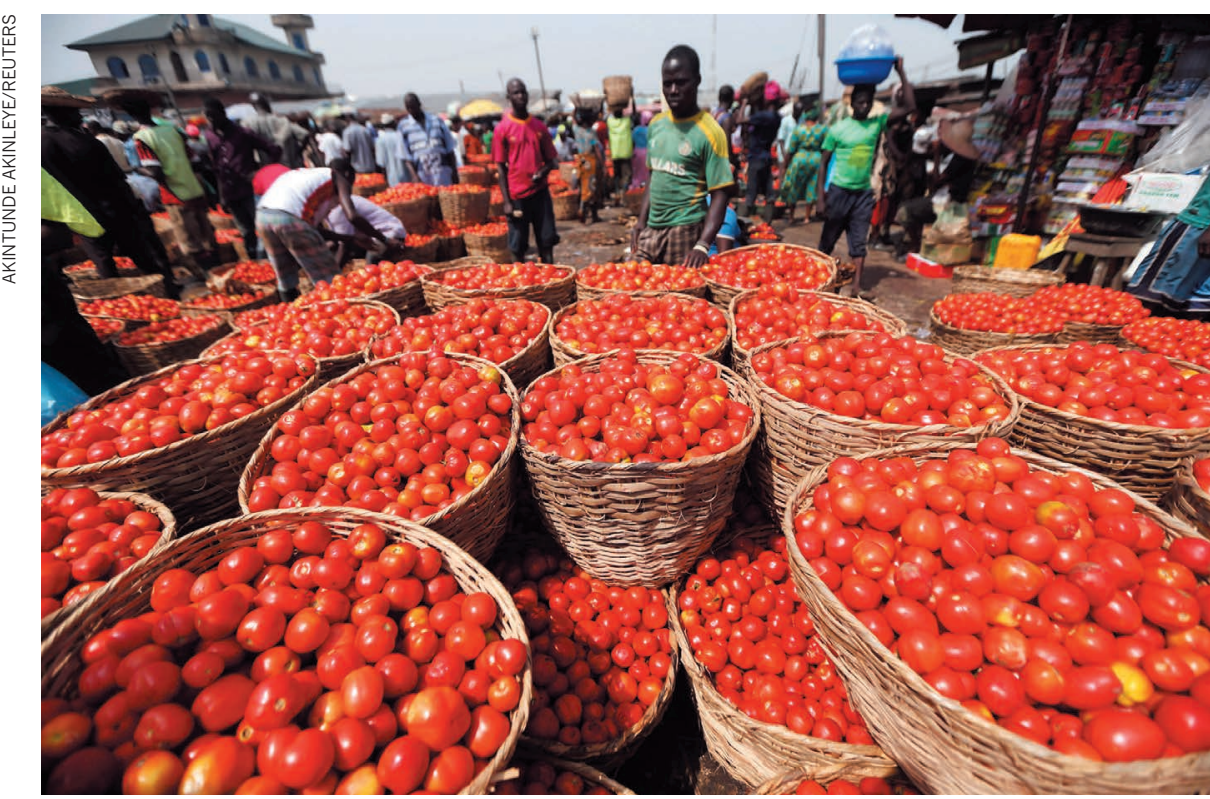

Swapping wicker baskets for crates provided by packaging firms better protects tomatoes in transit.

food giants find it hard to access financial services. These companies are too high-risk to attract investment from banks and tend to be ineligible for microfinance schemes that provide small loans (around \$1-10) to very poor households. Governments could create financial instruments, such as low-interest loans for nutritious-food suppliers, to meet their needs.

Governments could also develop effective 'quality seals' targeted to specific groups, such as street-food vendors or institutional caterers, to certify that a food is healthy (or unhealthy). Assessments suggest that 'traffic-light systems' of red, amber and green ratings used in the United Kingdom and Australia, or the black stop-sign labels used in Chile, seem to be effective ways to steer people towards better nutrition ${ }^{14}$.

Create demand for healthy foods. Business leaders often tell me that if consumers wanted more nutritious foods, they would meet that demand. Yet businesses shape demand, and some bend it towards unhealthy foods - mainly because these are easy to produce at scale and to transport, market and sell at a significant mark-up.

Governments must take the lead when it comes to building consumer demand for healthy foods - much as they have changed people's behaviour around smoking and drink-driving. That means partnering with non-profit foundations and creative agencies to make health messages about food accurate and memorable instead of worthy and dull. In the United Kingdom, the Food Foundation, a non-profit organization working to improve nutrition, collaborated with the creative agency ifour in late 2017 to create messages and images that tap into children's interest in superheroes to encourage them to eat vegetables. The impact of this has not yet been rigorously evaluated, but a related initiative targeting households in a province of Ecuador in 2015 increased egg consumption to one a day in 6- to 9-month-olds, and improved growth ${ }^{15}$. Providing such incentives will boost consumer demand and thus encourage companies to meet it.

Create models to emulate. Both governments and businesses need evaluated examples of things they can do together that work.

Much of the evidence for the effectiveness of public-private partnerships comes from other sectors, such as health, infrastructure and education; from the unpublished reports of public and private organizations; or from the minds of those involved. canmalkeithard A 2016 literature for businesses to review concluded dogoodthings that "there are few for nutrition." independent, rigorous assessments of the impact of commercial sector engagement in nutrition". ${ }^{16}$

UN agencies, non-governmental organizations, businesses, researchers and nutrition champions need to do a better job of disseminating the lessons learned, for instance by creating a knowledge repository. This could be similar to the World Bank's free-to-access website on public-private partnerships for the building of roads, ports and other infrastructure (see go.nature.com/2ptdgqm).

Name and fame - or shame. Businesses can derail public-health initiatives and distort publicly available research to suit their own ends. For instance, a 2015 investigation by the British Medical Journal found that researchers at UK advisory bodies had received funding from major soft-drinks companies ${ }^{17}$. How exactly this affects research is not yet known, but it clearly undermines trust.

Likewise, governments can make it hard for businesses to do good things for nutrition - either through a lack of awareness or through poor planning. For example, some governments impose a tariff on imported premix, the micronutrient-rich compound that is used in small amounts to fortify staple foods, such as wheat or maize (corn). The tariff can dissuade food processors from implementing this cost-effective publichealth strategy.

A ranking scheme is needed to flag which governments and businesses are doing positive or harmful things for nutrition.

One game changer has been the Access to Nutrition Index (www.accesstonutrition.org). Released every three years, the index uses mainly self-reported information to evaluate the world's 22 largest multinational food and beverage manufacturers on their policies, practices and performance in relation to under-nutrition and obesity. Although it has begun to produce national reports, further national, independent and evidence-based assessments are needed.

The World Bank currently ranks 190 national economies according to how easy it is to start and operate a firm in that country. In principle, governments could similarly be ranked according to how easy they make it for businesses to produce available, affordable and desirable nutritious food that can, for instance, reduce the proportion of women experiencing anaemia or the percentage of children who are obese. Such assessments (perhaps conducted jointly by the World Bank, the WHO and the Food and Agriculture Organization of the UN) would help to reveal what kinds of government action actually help businesses to improve nutrition.

Foster public-private engagement. More dialogue between people working on nutrition in the public and private sectors will catalyse all these other steps.

Major differences in culture, language and networks exist between those concerned with food systems in the public and private sectors. In fact, before I joined GAIN, I talked and worked only with academics, programme implementers and policymakers.

The accountability measures I describe could help those in the public sector to decide who to partner with. Also, thorough and pragmatic conflict-of-interest guidelines will help to reveal when public-health goals are at risk.

There are numerous ways to foster more dialogue. Panels at conferences should include participants from both sectors. Public funders could incentivize joint 
proposals for nutrition research from public-private collaborations. Companies and public-sector organizations could set up staff exchange programmes. And executive-level courses, either at universities or in private institutions, could bring together professionals from both sectors to learn from instructors drawn from these two worlds.

Many analysts (myself included, in the past) have drawn parallels between 'big tobacco' and 'big food'. In both cases, major corporations wield immense power over consumers and society, and their products are capable of doing considerable harm.

But there are crucial differences. Unlike big tobacco, big food is not the only player. There are small- and medium-sized companies too. And big tobacco cannot make tobacco that promotes public health, whereas big food can and does produce nutritious, sustainable foods. Motivated by both carrots and sticks, the industry can produce more - at a lower price.

Lawrence Haddad is executive director of the Global Alliance for Improved Nutrition (GAIN) in Geneva, Switzerland.

e-mail:lhaddad@gainhealth.org

1. Briggs, A. D. M. et al. Lancet Public Health 2, e15-e22 (2017)

2. Nakhimovsky, S. S. et al. PLOS ONE 11, e0163358 (2016).

3. Colchero, M. A., Rivera-Dommarco, J., Popkin, B. M. \& Ng, S. W. Health Aff. 36, 564-571 (2017)

4. Save the Children. Don't Push It: Why the Formula Milk Industry Must Clean Up Its Act (Save the Children, 2018)

5. Cairns, G., Angus, K., Hastings, G. \& Caraher, M. Appetite 62, 209-215 (2013)

6. Afshin, A. et al. PLoS ONE 12, e0172277 (2017).

7. World Health Organization. Global Nutrition Policy Review 2016-2017 (DRAFT). (WHO, 2018).

8. International Food Policy Research Institute. Global Nutrition Report 2016: From Promise to Impact: Ending Malnutrition by 2030 (IFPRI, 2016)

9. Alexander, E., Yach, D. \& Mensah, G. A. Glob. Health 7, 26 (2011).

10.Turner, T., Spruijt-Metz, D., Wen, C. K. F. \& Hingle, M. D. Pediatr. Obes. 10, 403-409 (2015).

11.University of Sydney Impact Evaluation Consortium for Global Alliance for Improved Nutrition. Effectiveness of an Integrated Program to Reduce Maternal and Child Malnutrition in Indonesia: Cross-Sectional Impact Evaluation Report (Global Alliance for Improved Nutrition, 2017)

12.Lipinski, B. et al. Reducing Food Loss and Waste. Working Paper (World Resources Institute, 2013).

13.Altai Consulting. USAID-GAIN Case Study Annex to Technical Report on the MNF Assessment (USAID/GAIN, 2016)

14.Cecchini, M. \& Warin, L. Obes. Rev. 17, 201-210 (2016).

15. Iannotti, L. L. et al. Pediatrics 140, e20163459 (2017).

16. Hoddinott, J. F., Gillespie, S. \& Yosef, S. World Rev. Nutr. Diet. 115, 233-238 (2016)

17.Gornall, J. Br. Med. J. 350, h231 (2015).

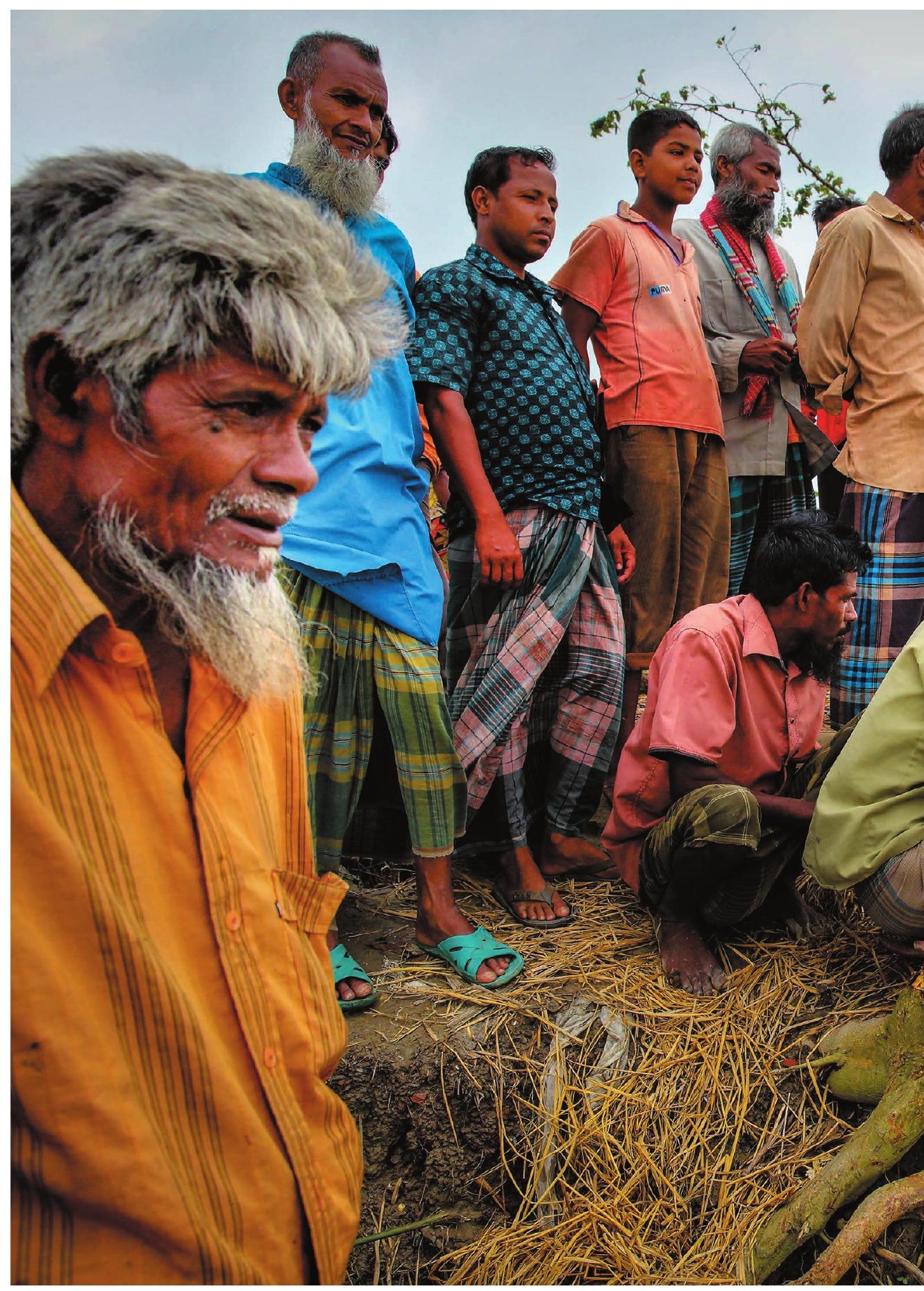

\section{Developing countries must lead on solar}

\section{geoengineering research}

The nations that are most vulnerable to climate change

must drive discussions of modelling, ethics and governance, argue A. Atiq Rahman and colleagues. 